Artigo com copyright pertencente à revista em que foi publicado.

Pode ser obtido nas plataformas B-On ou Science Direct ou através da página web da revista.

Biosystems Engineering 94 (4) (2 006 ) 525-533

doi:10.1016/j.biosystemseng.2006.04.011

\title{
Relationship between Distance to Flow Accumulation Lines and Spatial Variability of Irrigated Maize Grain Yield and Moisture Content at Harvest
}

\author{
J.R.Marques da Silva;L.L.Silva \\ Rural Engineering Department, Évora University, Apartado 94, 7002-554 Évora, Portugal; email: \\ jmsilva@uevora.pt; 11silva@uevora.pt
}

\begin{abstract}
Analysis of yield variability factors is an important issue in order to obtain information that allows the delineation of areas with stable yield patterns for application of precision agriculture techniques. The objective of this study was to evaluate the spatial and temporal variability of yield and grain moisture content at harvest with their distance to flow accumulation lines, based on 3-yr data of centre-pivot irrigated maize crop in Southern Portugal. Yield data were collected over the period from 2002 to 2004 and divided into data sets relating to nine classes of distances to flow accumulation lines. Based on these data sets, the relation between yield and grain moisture content at harvest with distance to flow accumulation lines was analysed. Results show that there is an increase in yield with the decrease of distance to flow accumulation lines, both in years with normal or above-normal applied irrigation water. In situations where insufficient irrigation water was applied, grain moisture content at harvest shows an increase as distance to flow accumulation lines decreases, but in years in which more irrigation water was applied, less grain moisture content at harvest near the flow accumulation lines was observed.
\end{abstract}

